\title{
EDITORIAL
}

\section{CLINICS HAS AN IMPACT FACTOR}

\author{
Mauricio Rocha e Silva
}

doi: $10.1590 / \mathbf{S 1 8 0 7 - 5 9 3 2 2 0 1 0 0 0 0 6 0 0 0 0 1}$

Our first Impact Factor comes five years after the first CLINICS issue circulated and we are extremely happy to inform our readers that Clinics achieved IF $=1.591$, which is the third highest ever for any Brazilian Journal. This IF was achieved with $21 \%$ of autocites, perfectly within the ethical limits set by ISI-Thomson. One other piece of good news is the fact that slightly more than $80 \%$ of the articles we published in 2007-2008 were cited in 2009. This is the first near-first-world result we can be proud about. It allows us to look forward to substantial improvements in the years to come.

Apart from our local success, the new JCR-ISI Impact Factors contain a very substantial set of positive novelties regarding Brazilian Scientific publications in general. The total number of included journals in the Science and Social Sciences Citation Indexes rose 132\%. As shown in Table 1, this by far the largest relative increase for any of the BRICK countries (I am sure that it is totally acceptable to rank South Korea together with the 4 other fast emerging nations as far as science is concerned).

Table 1 - BRICK COUNTRY JOURNALS in ISI - THOMSON (2008-2009)

\begin{tabular}{cccc}
\hline COUNTRY & $\begin{array}{c}\text { ISI JOURNALS } \\
2008\end{array}$ & $\begin{array}{c}\text { ISI JOURNALS } \\
2009\end{array}$ & $\begin{array}{c}\text { PERCENT } \\
\text { INCREASE }\end{array}$ \\
\hline BRAZIL & 31 & 72 & $132 \%$ \\
\hline RUSSIA & 114 & 124 & $9 \%$ \\
INDIA & 49 & 72 & $47 \%$ \\
\hline PR CHINA & 87 & 122 & $40 \%$ \\
KOREA & 45 & 72 & $60 \%$ \\
\hline
\end{tabular}

A number of factors should be noted here: (a) ISI THOMSON have clearly adopted a policy of enhancing the representation of periodicals from non-first world countries;

Hospital das Clínicas, Faculdade de Medicina da Universidade de São Paulo - São Paulo/SP, Brazil.

mrsilva36@hcnet.usp.br (b) CAPES, the Brazilian Ministry of Education Agency in charge of Graduate Education (amongst other things) and SciELO, the Brazilian based Scientific Electronic Library Online, have been extremely proactive in the enhancement of quality of Brazilian publications and vis-a-vis ISI-Thomson and Scopus in promoting inclusion. Over the next 1-2 years the number of Brazilian Journals listed in both databases will keep on increasing substantially.

However, this is only part of the story: the 2009 Science Citation Index contains more positive news about Brazilian periodicals. In the chapter of Impact Factor one of the newly included journals crossed the barrier of IF 3.000, but the best news is that our most cherished journal, Memórias do Instituto Oswaldo Cruz, Brazil's oldest continuously published scientific periodical crossed the IF 2.000 line. Eight other journals (four of which newly added) crossed the IF 1.000 line. Never before had any Brazilian journal been above IF 1.500 and never before had we ever had more than four journals above IF 1.000. In terms of ranking within the BRICK countries (Table 2) we have more journals in 2009 at every level of ranking in comparison to 2008 .

Table 2 - IMPACT FACTOR RANKS AMONG BRICK COUNTRIES (2008 - 2009)

\begin{tabular}{ccc}
\hline $\begin{array}{c}\text { Impact Factor Ranking (Brazilian } \\
\text { journals among the BRICK countries) }\end{array}$ & 2008 & 2009 \\
\hline Top Ten & 0 & 1 \\
\hline Top Twenty & 1 & 2 \\
Top Fifty & 5 & 8 \\
\hline Top hundred & 8 & 11 \\
\hline
\end{tabular}

The Peoples' Republic of China is clearly dominant here, with five journals within the top ten, followed by South Korea with three, then Brazil and Russia with one journal each.

Eigen Factor is a relatively recent metric addition to the ISI Thomson arsenal. It is probably a more sensitive tool for measuring quality. In this department, Brazil has also 
improved, even though there is still a very long way to go. Table 3 shows that in 2008, three Brazilian journals finished in the top twenty, five in the top fifty and that was all: no Brazilian journal finished between $51^{\text {st }}$ and $100^{\text {th }}$; this year for the very first time there is one Brazilian journal in the top ten, three journals in the top twenty, seven journals made the top fifty, and in the top hundred we have more than doubled. Even though we are improving, this definitely sounds a warning bell. Compared to Impact Factors, Eigen Factors are a far better measure of quality and Brazilian periodicals must still strive to improve.

Once again, the Peoples' Republic of China is dominant with five journals; Russia comes next with two, while Brazil, India, and South Korea close the list with one journal each. Nevertheless, it should be noted that even though numbers are similar, the actual journals in the Impact and Eigen Factor ranks are somewhat different. Thus it is great to see that Memórias do Instituto Oswaldo Cruz is highly ranked in both metrics.
Table 3 - EIGEN FACTOR RANKS AMONG BRICK COUNTRIES (2008 - 2009)

\begin{tabular}{ccc}
\hline $\begin{array}{c}\text { Eigen Factor Ranking (Brazilian journals } \\
\text { among the BRICK countries) }\end{array}$ & 2008 & 2009 \\
\hline Top ten & 0 & 1 \\
Top twenty & 3 & 3 \\
Top Fifty & 5 & 7 \\
Top hundred & 5 & 11 \\
\hline
\end{tabular}

One final word about Memórias do Instituto Oswaldo Cruz: they have become the first Brazilian Journal to join the top ten Eigen Factor in the BRICKT league. As far as this Editor is concerned, this is the top piece of news. If example is the best kind of leadership, then it is for all of us in Brazil to try to follow Memórias. It is not something that will come overnight as some spectacular jump in Impact Factor. It is rather something that will take time to accomplish. But we do have time. We can and must do better. 